\title{
Prof. Henrik Petrowsky: complex hepatobiliary and pancreatic surgery
}

Submitted Nov 04, 2019. Accepted for publication Nov 06, 2019.

doi: 10.21037/hbsn.2019.12.06

View this article at: http://dx.doi.org/10.21037/hbsn.2019.12.06

\section{Expert's introduction}

Prof. Henrik Petrowsky (Figure 1) is a Professor of Surgery and Vice-Chair of the Department of Surgery and Transplantation at the University of Zürich, Switzerland. He serves as Program Director of the HPB Surgery and Liver Transplant Fellowship at the Swiss HPB and Transplant Center Zurich. Prof. Petrowsky is heading the Liver and Pancreas Tumor Center, which is embedded in the Comprehensive Cancer Center Zurich at the University Hospital Zurich. His current practice consists of liver transplantation and HPB surgery. His research interests have mirrored his clinical work mainly focusing on translational and outcome research in liver transplantation and hepatobiliary surgery.

Prof. Petrowsky received his medical degree from the Johann Wolfgang Goethe University in Frankfurt, Germany. He spent a 2-year research fellowship at Memorial Sloan-Kettering Cancer Center in New York and completed his training in general surgery and hepatobiliary surgery at The University Hospital in Zurich, Switzerland. In 2009, he completed the Multi-Organ Transplant Fellowship at the University of California Los Angeles and joined the faculty of the University of California Los Angeles as Assistant Professor of Surgery-in-Residence and liver transplant attending.

\section{Interview}

HBSN: Can you give a general picture of your presentation to those who can not attend this meeting?

Prof. Petrowsky: The focus of my speech and my talk was to show how the different techniques and methods of augmentation of the liver, which will remain in the body after resection, can assist liver resection either again in a one-stage or two-stage procedure. Also, we spoke about combining techniques.

\section{HBSN: What are the recent breakthroughs in your study?}

Prof. Petrowsky: I think that look exclusively in my study but overall is that to increase resectability exactly by these kinds of techniques where we can augment the liver tissue. So, in the end, it's safer for the patients. Second also that we can resect probably more patients than that in the past.

\section{HBSN: Ok, what are the aims of your future study?}

Prof. Petrowsky: Aims of my future study is in the field of liver resection, its translational research. We look into things where we might go from bench to bedside or even from bedside to bench and just also improve principles and reproducibility of the findings. But overall, the goal of the research is to improve outcome of patients, so my focus is on clinical outcome research.

HBSN: As we all know, you won the Outstanding Reviewer Award HBSN in 2019, so can you share with us some experience of reviewing manuscripts?

Prof. Petrowsky: Well, it's pretty much like the other that I am really going for many journals and these journals especially your journal is focused on liver disease. So, it's a very special and organ specialized journal and you have to read and learned to see whether the paper would fit or not fit in the journal.

HBSN: You have been given various honors and awards, so do you have any words for young people to encourage them?

Prof. Petrowsky: To encourage people who are interested in academic work, you could probably motivate them that you have a lot of awards for instance, for the best clinical paper or for the best scientific paper. If they have a chance, 


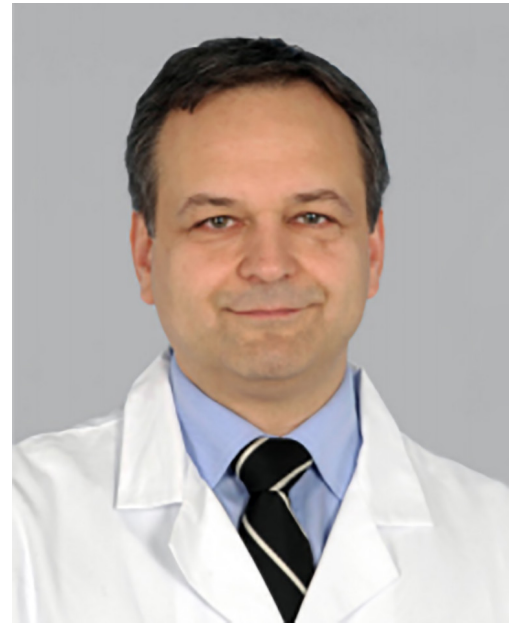

Figure 1 Prof. Henrik Petrowsky.

they can, not only write the paper, but they should be awarded for their work. Or possibly, even something special should be awarded to young people who are also involved in teaching to allow them to engage with younger students so that they will also be highly welcomed and interested in becoming doctors.

\section{HBSN: When did you first heard about this journal?}

Prof. Petrowsky: When I was asked to review for paper.

\section{HBSN: What do you think of the journal when you know that it was launched by Chinese people?}

Prof. Petrowsky: I think China has a large population, very large population like India and it's also special in Asia that has very little bit more different diseases than we have in Europe. So therefore, I think, this region is very large.
China, Japan and Korea and perhaps India, this journal could basically launch in all these different regions, and also focus on their needs of this special geographic region. I mean it probably heavily focuses on some disease that are very common here.

\section{HBSN: What do you think of Dr. Yi Lei Mao?}

Prof. Petrowsky: I think he is doing a very good job pushing the journal. Also, I think he really puts a lot of effort and energy in his work. This journal is very known worldwide and I think if you look at the impact factor, the quality of papers I think it's growing and he told me there is still room to improve.

HBSN: So, what are your expectations to our journal's future?

Prof. Petrowsky: First, I think the minimum goal is that it can defend the position where it is right now. As it grows further, one of the most important thing is how many citations you get, which is related with the impact factor.

\section{Acknowledgments}

I would like to express my heartfelt gratitude for Prof. Petrowsky for accepting this interview. Also, thanks to $H B S N$ for giving me this opportunity.

\section{Footnote}

Conflicts of Interest: The authors have no conflicts of interest to declare.

(Science Editor: Ruolei Shi, HBSN, editor@thehbsn.org)
Cite this article as: Shi R. Prof. Henrik Petrowsky: complex hepatobiliary and pancreatic surgery. Hepatobiliary Surg Nutr 2020;9(1):124-125. doi: 10.21037/hbsn.2019.12.06 